Psychotherapy Research, 2015

http://dx.doi.org/10.1080/10503307.2015.1080877

Routledge

EMPIRICAL PAPER

\title{
What do "interpersonally sensitive" supervisors do and how do supervisees experience a relational approach to supervision?
}

\author{
KATHARINE S. SHAFFER \& MYRNA L. FRIEDLANDER \\ Department of Education, Division of Counseling Psychology, University at Albany/State University of New York, Albany, \\ NY, USA \\ (Received 27 May 2015; revised 28 fuly 2015; accepted 29 fuly 2015)
}

\begin{abstract}
Objective: In two investigations, we identified explicitly relational supervision strategies and examined whether use of these strategies was associated with perceptions of the supervisory alliance and evaluations of the supervisor. Method: First, ratings by nine supervision researchers identified five clearly relational in-session strategies (focus on countertransference, exploration of feelings, attend to parallel process, focus on the therapeutic process, focus on the supervisory alliance) in the Critical Events model of supervision. Based on these expert ratings, we created and assessed the Relational Behavior Scale (RBS). Results: Analyses with two samples of supervisees at all levels of training supported the measure's reliability and factorial validity. The RBS's validity was further indicated by its unique association with the "interpersonally sensitive" style of supervision. In both studies, supervisees perceived more frequent use of relational behavior on the part of psychoanalytic/psychodynamic/ humanistic supervisors than cognitive-behavioral supervisors. Moreover, as hypothesized, supervisors' use of relational behavior in a specific session mediated the association between trainees' alliance perceptions and evaluations of their supervisors in that session. Conclusion: The identification of specific in-session supervision behaviors that explain one way in which a strong alliance contributes to trainees' positive experiences of their supervisors has implications for supervision theory, research, and practice.
\end{abstract}

Keywords: alliance; process research; psychotherapist training/supervision/development

The unique aspects of the supervision process have long been of interest to psychologists. In more recent scholarship, authors have emphasized the explicitly evaluative nature of supervision and its real-life consequences for psychotherapy trainees. Indeed, it has become abundantly apparent that a poor supervisory experience can harm a trainee personally as well as professionally (e.g., Ellis et al., 2014; Nelson \& Friedlander, 2001; RamosSánchez et al., 2002).

Only recently have researchers begun to identify specific elements of a high-quality supervision experience. Early theorists, rather than attempting to understand variability in the quality of the supervision experience, described the different contexts in which supervision takes place, the different formats of supervision, and the ways in which supervisors work with trainees at different developmental levels (e.g., Hess, 1980; Stoltenberg, McNeill, \& Delworth, 1998).

To advance theory on supervision processes, Friedlander and Ward (1984) initiated a program of research to identify effective dimensions of supervisory style. These authors situated supervisory style (defined as "the supervisor's distinctive manner of approaching and responding to trainees and of implementing supervision") as an intermediate source of variability among supervisors, linked to the more global concept theoretical orientation and to the more specific concepts supervision strategy (defined as "a series of goal-directed behaviors”), format (e.g., group supervision), and technique (e.g., role play) (p. 541).

In developing the Supervisory Styles Inventory (SSI), Friedlander and Ward (1984) began by

Correspondence concerning this article should be addressed to Katharine S. Shaffer, Division of Applied Behavioral Sciences, University of Baltimore, 1420 N. Charles St., Baltimore, MD 21201, USA. Email kshaffer@ubalt.edu 
interviewing 20 experienced supervisors with a local "good reputation" (p. 544). From an inductive analysis of these interviews, the authors distinguished the interpersonally sensitive (IS) supervision style (represented by items like intuitive, perceptive, reflective, and therapeutic), which reflects psychoanalytic theorists' emphasis on the relational aspects of supervision (e.g., Eckstein \& Wallerstein, 1972; Kell \& Mueller, 1966), from the task-oriented (TO) style (e.g., structured, focused, goal-oriented, prescriptive, and concrete), which reflects a focus on client material and the supervisor's role as an "evaluative expert” (p. 548). In a series of quantitative studies, the two supervisory styles emerged as empirically distinct from one another and distinct from the attractive (ATT) style (e.g., friendly, flexible, trusting, warm, and open), which reflects a generally collegial approach to supervision. With respect to supervision quality, Friedlander and Ward found that, "the commonality between supervisory style and four aspects of satisfaction is primarily represented by trainees who report their supervisors as highly IS also reporting positive effects of supervision on their professional development and clients' progress" (p. 548).

Despite over 30 years of scholarship on interpersonal aspects of supervision, including the supervisory working alliance (Bordin, 1983) and supervisor responsiveness (Friedlander, 2012, 2015), we know little about the actual behaviors that reflect an explicitly relational approach to supervision. That is, what do "interpersonally sensitive supervisors" do, in session, to enhance the supervisory relationship and to contribute to a supervisee's positive experience of supervision? Answering this question was the objective of the present program of research.

One relational strategy has long been in the supervision literature, namely identifying parallel processes. Early psychoanalytic authors (Doehrman, 1976; Searles, 1955) defined the parallel process phenomenon as unconscious processes in a supervisee's therapy relationships that are played out in the supervision relationship, and vice versa. More recent authors refer to parallel processes as complementary interpersonal interactions in the supervisee's work with clients, such as helpless client/directive therapist, that carry over to the supervisory relationship, for example, helpless supervisee/directive supervisor, and vice versa. The explanation for the parallel process phenomenon is that supervisees are in a position of authority ("one up") in their therapy relationships but are in a subordinate position ("one down") with their supervisors (e.g., Doehrman, 1976; Friedlander, Siegel, \& Brenock, 1989; Tracey, Bludworth, \& Glidden-Tracey, 2012). It remains to be determined, however, to what extent examining parallel processes is particularly meaningful for supervisees' learning.

Attending to parallel process is one of 11 interactional strategies in Ladany, Friedlander, and Nelson's (2005, in press) Critical Events model of the supervision process. In describing their pragmatic approach, Ladany et al. (2005) identified seven specific critical supervision tasks that tend to occur frequently across training environments, including repairing gender-related misunderstandings, heightening multicultural awareness, managing sexual attraction, remediating skill difficulties and deficits, negotiating role conflicts, working through countertransference, and addressing problematic attitudes and behavior. According to these authors, within the context of a strong working alliance, by using specific interactional strategies such as attend to parallel process, supervisors move back and forth between a focus on the supervisory relationship and a focus on the supervisee's therapy relationship(s) in order to bring the event to a meaningful conclusion. As in the figure/ground phenomenon, at times during supervision the therapy relationship is the figure, such as when the supervisee's work with a client is being considered, and the supervisory relationship is the ground, whereas at other times the supervisory relationship is the figure, such as when the supervisee's reaction to supervision is being discussed, and the therapy relationship is the ground.

Consider, for example, a supervision event that begins with a discussion of a client's presenting concerns. The supervisor notices that the supervisee, "Taylor," seems uncomfortable. Moving from a focus on the therapy relationship to the supervision relationship, the supervisor inquires about Taylor's feelings in the present moment (exploration of feelings). Taylor responds by explaining that she is having a difficult time liking her client. The supervisor then switches strategy to a focus on countertransference. After several minutes discussing the possible basis for Taylor's negative reaction to her client, the supervisor checks in with Taylor about her comfort sharing such personal material in supervision (focus on the supervisory alliance). When Taylor indicates that their discussion is helping her feel differently toward her client, the supervisor points out that using a similar here-and-now focus might be helpful in Taylor's work with the client (attend to parallel process). To conclude the discussion, the supervisor brings the conversation back around to ways that Taylor might enhance the working alliance with her client (focus on the therapeutic process). This countertransference event is considered to be successfully "resolved" when Taylor realizes that she can use her new self-awareness to 
understand her client better and then apply this new understanding to her actual therapeutic work with the client.

Ladany et al.'s (2005, in press) identification of critical events and interactional sequences (defined as one or more speaking turns) to bring these events to a successful resolution represented a step forward in our understanding of high-quality supervision processes. There has, however, been little research on this model. What is known, in general, is that negative events in supervision tend to have a profound influence on supervisees' feelings (e.g., Nelson \& Friedlander, 2001); moreover, negative events detract from the supervisory alliance (e.g., Bertsch et al., 2014; Ramos- Sánchez et al., 2002) and inhibit trainees' inclination to disclose relevant material to their supervisors (Walker, Ladany, \& Pate-Carolan, 2007). What is not known is how effective supervisors behave so as to create an interpersonal environment that is most conducive to supervisees' professional growth and development.

In our first study, designed to better understand explicitly relational behavior in supervision, we began by identifying which of the 11 interactional strategies in Ladany et al.'s (2005, in press) Critical Events model are most clearly relational. (In order to distinguish these in-session interactions from the more general "interpersonally-sensitive style" of supervision, we decided to call them relational rather than interpersonal). Next, we assessed the initial reliability and construct validity of a measure developed from these relational strategies. In terms of validity, based on Friedlander and Ward's (1984) model of sources of variability in supervision we hypothesized that greater use of relational behavior in session would distinguish (i) supervisors with a psychodynamic/humanistic theoretical orientation from those with a cognitive-behavioral approach, and (ii) the "interpersonally sensitive" style of supervision from the "task-oriented" and the generally "attractive" styles.

\section{Study 1: Scale Construction and Initial Validation}

\section{Method}

Participants. Participants were $71 \mathrm{PhD}$ and PsyD students in clinical $(5.4 \%)$ or counseling (94.6\%) psychology, recruited via individual emails to the training directors of doctoral programs accredited by the American Psychological Association (APA). Demographic data indicated that on average, participants were 29.42 years of age, $S D=5.82$. Most participants were women $(87.8 \%) ; 75.7 \%$ were European-American/White, $9.5 \%$ were Asian/Asian
American, $5.4 \%$ were African American/Black, $5.4 \%$ were multiracial, $2.7 \%$ were Latino/a, and $1.4 \%$ indicated "other." Most participants were in either their first $(10.8 \%)$ or an advanced practicum $(68.9 \%)$; the remainder were interns $(17.6 \%)$. Participants reported working with an average of 6 weekly clients in university counseling centers (40.5\%), community clinics $(28.4 \%)$, hospitals $(20.3 \%)$, or other settings $(10.8 \%)$. On average, they had had 31.1 months of supervised experience, $S D=18.7$, with $M=1.3 \mathrm{hr}$ of weekly supervision, $S D=0.65$.

Most participants indicated that their supervisors were European-American/White $(82.4 \%)$ men $(56.8 \%)$. In terms of theoretical orientation, participants reported that their supervisors were psychodynamic/psychoanalytic $(25.7 \%)$, cognitive-behavioral $(23.0 \%)$, integrative $(18.9 \%)$, humanistic $(14.9 \%)$, or family systems $(4.1 \%) ; 13.9 \%$ of participants reported being unsure of their supervisor's theoretical orientation.

Instruments. Relational behavior scale. To construct the Relational Behavior Scale (RBS), we began by determining which of the 11 behavioral sequences in Ladany et al.'s (2005, in press) Critical Events model of supervision are most clearly relational. To do so, we asked nine expert supervision researchers (six women, three men) to rate each sequence on a 1 to 5 scale, where $1=$ task-oriented, $3=$ both, and $5=$ interpersonal. The experts were provided with Ladany et al.'s definition of each sequence (see Appendix 1). For example, Ladany et al. defined the sequence focus on the therapeutic process as " $[\mathrm{a}]$ discussion about what is taking place between the supervisee and client, i.e., the kinds of interactions that occur, the strength of the therapeutic alliance, and how the client sees the supervisee's behavior in relation to self and vice versa" (p. 16). (Whereas Ladany et al. used the term interactional sequence to denote the possibility that the supervisor's use of each behavior could extend over several talking turns, for purposes of clarity, we chose to use the term behavior.)

Results of the expert ratings showed that 5 of the 11 sequences were viewed as most clearly relational, defined as $M d n \geq 4$ on the 5-point scale. These five sequences, which became the scored items in the RBS, are exploration of feelings, focus on the therapeutic process, attend to parallel process, focus on countertransference, and focus on the supervisory alliance. The remaining six sequences were retained in the RBS as filler items so that the relational nature of the measure would not be readily intuited by participants. 
In this first study with the RBS we asked the 71 trainee participants to rate each of the 11 items in terms of the extent to which each behavior was used by their primary individual supervisor in the most recent supervisory session. As we had done with the experts, the measure included Ladany et al.'s (2005) operational definitions. Participants rated each item on a 5 -point scale ranging from $1=$ not at all to $5=$ very much, so that total scores on the 5 key behaviors could range from 5 to 25, with higher scores reflecting a greater perceived use of the five relational behaviors during a specific supervision session. Based on this sample, the internal consistency reliability of the RBS was $\alpha=0.85$.

Note that the RBS directions ask respondents to consider only their most recent supervision session. This aspect of the scale is important for two reasons: First, a supervisee's recall of the most recent session is likely to be better than recall of the entire supervision experience, the length of which can vary greatly across supervisees. Second, it is likely that all 11 sequences in the RBS are used at some point in most supervision relationships; thus, directing participants to focus on the entire supervision experience would limit variability in the scores and, more importantly, their meaningfulness. For these reasons, we constructed the RBS to assess the degree of focus on relational behavior within a single, recent supervision session.

Supervisory styles inventory. The multidimensional SSI (Friedlander \& Ward, 1984), widely used in supervision studies, has parallel forms for trainees and supervisors. Each measure has 33 unipolar items, 8 of which are fillers. We used the trainee version, which asks participants to rate their primary supervisor's style of supervision. The three orthogonal SSI scales are IS (8 items, e.g., perceptive, reflective, invested, and therapeutic), TO (10 items, e.g., structured, focused, prescriptive, and explicit), and ATT (7 items e.g., friendly, flexible, warm, and supportive). Each item is rated from $1=$ not very and $7=$ very; the score for each scale is the sum of the raw scores divided by the number of items in the scale, so that higher scores (range 1-7) indicate a greater endorsement of each supervisory style.

The SSI's initial construct validity was supported by factorial analyses with both supervisor and supervisee participants. Additionally, the SSI scales discriminated between supervisees at different levels of training and between supervisors with different theoretical orientations. That is, psychodynamic/humanistic supervisors endorsed a significantly more IS style, whereas cognitive-behavioral supervisors endorsed a significantly more TO style (Friedlander \& Ward, 1984). Moreover, significant correlations were reported between the SSI styles and (i) trainees' willingness to work with different model supervisors and (ii) satisfaction with supervision.

In developing the SSI, Friedlander and Ward (1984) reported robust internal consistency reliabilities, $\alpha \mathrm{s}=0.84$ to 0.89 , and test-retest reliabilities ranging from 0.78 to 0.94 . In the present sample, $\alpha \mathrm{s}=0.90$ (IS), 0.86 (TO), and 0.96 (ATT).

\section{Results}

Relational behavior and theoretical orientation. First, we compared participants' scores by their supervisors' theoretical orientation. Specifically, we predicted a significant difference, with higher RBS scores for supervisors who were reportedly either psychoanalytic, psychodynamic, or humanistic $(n=30)$ in contrast to cognitive-behavioral $(n=17)$. Results supported this hypothesis, $F(1$, $45)=8.68, p=.005, \eta^{2}=0.16$. That is, RBS scores were significantly higher for psychodynamic/psychoanalytic/humanistic supervisors $(M=16.33, S D=$ 5.96) as compared with cognitive-behavioral supervisors $(M=11.53, S D=4.09)$.

Relational behavior and supervisory style. To test the convergent validity of the RBS, we hypothesized that RBS scores would be positively and uniquely related to the IS supervisory style. We further hypothesized that the RBS's divergent validity would be supported if we found no unique associations between RBS scores and either the TO or the ATT supervisory style.

The full regression model was significant, $F(3,67)$ $=35.03, p<.0001, R^{2}=0.61$, adj. $R^{2}=0.59$. Tests of the beta weights showed that, as hypothesized, only IS was a significant unique predictor of RBS, $t=7.48, p<.0001, r_{\text {(IS.AT,TO) }}^{2 y}=0.57$. In other words, while supervisory style accounted for roughly $60 \%$ of the variance in the in-session use of relational behaviors, only the IS style was uniquely predictive of these behaviors.

Discussion. Results of the initial assessments of the RBS measure supported its internal consistency reliability and its construct validity. Notably, perceptions of the supervisor's use of relational behavior were uniquely characteristic of the IS style, which is more explicitly relational than either the ATT or TO styles (Friedlander \& Ward, 1984). Moreover, like the IS supervision style, relational behaviors as measured by the RBS were significantly more characteristic of participants' psychodynamic/psychoanalytic and humanistic supervisors than their 
cognitive-behavioral supervisors. These findings prompted us to investigate the RBS measure further, particularly its applicability to trainees' evaluations of their supervision experience.

\section{Study 2: How do Supervisees Experience Relational Behaviors in Supervision?}

In this second study, with a broader sample of supervisees, we investigated whether the results of Study 1 would be replicated in terms of the RBS's reliability and its association with a supervisor's theoretical approach. We also tested the factorial validity of the scale and investigated its association with participants' experience of the supervision process. We reasoned that if, as Ladany et al. (2005, in press) theorized, in-session relational behavior is most effective within the context of a strong working alliance, then higher RBS scores in a specific session would at least partially explain the association between strong alliance perceptions and positive evaluations of the supervisor in that session.

\section{Method}

Participants. As in Study 1, volunteers for Study 2 were invited to participate in a study of "the types of relationships supervisors build with trainees in supervision." To obtain a broader sample than the RBS development sample, we recruited participants at all levels of training. The final sample included 141 trainees in counseling and clinical psychology doctoral programs $(78.7 \%)$ and master's programs $(21.3 \%)$ in mental health counseling, social work, and couple and family therapy. To be included in the sample, participants needed to be currently engaged in clinical work and receiving regular individual supervision, with the most recent supervision session occurring in the previous two weeks. Excluded were post-graduate trainees and trainees who were not seeing clients or whose supervision consisted solely of case management review.

Demographic data indicated participants' average age to be 27.91 years $(S D=5.06$; range $22-51)$, and most participants were European-American/White (77.3\%) women (80.9\%); 6.4\% were African American/Black, 5.7\% were Asian/Asian American, 5.0\% were Latino/a, $2.8 \%$ were multiracial, and $2.8 \%$ identified their race/ethnicity as "other." Most participants worked in college/university counseling centers or community agencies $(55.4 \%)$ and had no formal training in supervision $(60.3 \%)$. On average, participants worked with 6.57 clients per week $(S D$ $=4.42 ;$ mode $=7$ ), had $M=21.24$ months of clinical experience $(S D=18.52)$, spent $1.7 \mathrm{hr}$ in individual supervision weekly $(S D=3.77)$, and had been working with their primary supervisor for $M=5.86$ months $(S D=5.92$; range $1-36)$.

According to participants, most of their supervisors were European-American/White $(79.9 \%)$ women $(61.7 \%)$ with degrees in clinical or counseling psychology $(74.3 \%)$, who had received formal training in supervision $(75.2 \%)$. In addition, participants indicated that their supervisors' theoretical orientations were psychoanalytic/psychodynamic or humanistic (32.1\%), cognitive-behavioral (35.5\%), integrative/ eclectic $(15.6 \%)$, family systems $(2.8 \%)$, other (e.g., behavioral analysis, interpersonal, and narrative), or unsure $(13.5 \%)$.

Instruments. Relational behavior scale. As in Study 1, the RBS was used to assess participants' perceived use of relational behaviors by their primary supervisor in their most recent supervision session. The internal consistency estimate for the Study 2 sample, $\alpha=0.85$, was identical to that obtained in Study 1.

Working alliance inventory-trainee. We used the total score on the Working Alliance InventoryTrainee form (WAI-T; Bahrick, 1989), which is based on Bordin's (1983) conceptual model of the supervisory alliance. The WAI-T contains three subscales that assess a supervisee's perception of agreement on goals, agreement on tasks, and the emotional bond with a supervisor. Each subscale contains 12 items rated on a 7-point scale from 1 (never) to 7 (always). Items include, "The goals of these sessions are important to me" (Goals), "I am clear on what my responsibilities are in supervision" (Tasks), and "(Supervisor's name) and I trust one another" (Bond). We used the total score (range 36-252) rather than subscale scores due to their high intercorrelations, as reported by Bahrick.

Internal consistency reliability estimates tend to be high, for example, $\alpha=0.98$ in Walker et al. (2007). In terms of validity, Inman (2006) reported a significant positive relationship between WAI-T scores and satisfaction with supervision as well as perceptions of the supervisor's multicultural competence, and Ladany and Friedlander (1995) found a significant negative relationship between WAI-T scores and perceived role conflict and role ambiguity. Results of comparison tests revealed no significant differences on WAI$\mathrm{T}$ mean scores between the present sample and Bahrick's (1989) three samples, all $p s>0.01$. In the present sample $\alpha=0.97$.

Trainee personal reaction scale-revised. We used the Trainee Personal Reaction Scale-Revised (TPRS-R; Holloway \& Wampold, 1984), which is often used as a proxy for satisfaction with supervision. 
However, the authors designed three orthogonal dimensions of the TPRS-R to assess trainees' experience of a specific supervision session: Evaluation of Supervisor (e.g., "I was eager to hear what my supervisor had to say"), Evaluation of Self (e.g., "I sometimes felt like I was being put on-the-spot"), and Level of Comfort (e.g., "I sometimes resented my supervisor's attitude toward me"). Each subscale has four items rated on a 5-point scale from 1 (not characteristic of my present feelings) to 5 (highly characteristic of my present feelings). Items on the Evaluation of Self and the Level of Comfort scales are reverse scored. Summed subscale scores range from 4 to 20, and total scores range from 12 to 60 .

Reliability estimates for the subscales and total scale have ranged from 0.71 to 0.89 (Holloway \& Wampold, 1984; Ladany, Ellis, \& Friedlander, 1999; Olk \& Friedlander, 1992). In terms of validity, Olk and Friedlander found a negative relationship between TPRS-R scores and perceived role conflict and role ambiguity, and Ladany et al. reported a significant positive relationship between supervisees' Bond scores on the WAI-T and their TPRS-R scores.

Results of comparison tests showed no significant mean differences on total TPRS-R scores between the present sample $(N=141 ; M=48.03, S D=8.97)$ and those reported by Ladany et al. (1999; $N s=107 ; \quad M=48.51_{\text {pre-test }}, \quad S D=7.75_{\text {pre-test }}$ and $\left.M=48.58_{\text {post-test }}, S D=7.88_{\text {post-test }}\right)$. In the present sample, $\alpha \mathrm{s}=0.89$ (total score), 0.90 (Evaluation of Supervisor), 0.79 (Evaluation of Self), and 0.78 (Level of Comfort).

Procedure. Participants for this web-based study were recruited nationally and through training directors of clinical and counseling psychology doctoral programs and internships, as well as directors of master's programs in mental health counseling, social work, and couple and family therapy. Snowball sampling was also used in that participants were asked to forward the study link to other trainees of their acquaintance. The measures were administered in random order by PsychData.com software. Email addresses (not linked to survey responses) were requested for participants who chose to enter a drawing for a $\$ 10$ gift certificate to an online retailer.

\section{Results}

Preliminary analyses. From the original sample of 158 participants, 17 cases with $\geq 5 \%$ missing data were deleted. A missing completely at random test (Little, 1988) indicated that 33 other missing responses were omitted randomly, $\chi^{2}(2907)=$ 2982.83; $p=.160$. For this reason, expectation maximization (Schlomer, Bauman, \& Card, 2010) was used to impute values for these missing responses.

A one-way MANOVA indicated no significant order effects, Bartlett's test of sphericity, $F(3,135)$ $=226.08 ; p=.001$, Pillai's Trace $V F(9,405)$ $=.101, p=.123$. Thus we concluded that counterbalancing of the three measures minimized any threat to validity due to order of administration.

Ten outliers were examined using the DFBETA, Cook's distance, influence, and leverage statistics. Four cases exceeded the $\alpha=0.025$ criteria, $t(138) \pm$ 2.33 for studentized deleted residuals. Centered leverage statistics indicated that six cases exceeded the critical value, $(3 k / n=9 / 141)=0.06$, and graphical plots showed that these six participants reported relatively high WAI-T scores. When these cases were examined for contamination, no relationships were found with any of the demographic variables. Since no overlap existed among the 10 outlier cases, all of these cases were retained in the final sample $(N=141)$.

None of the assumptions for multiple regression was violated. Visual inspection of the matrix scatterplots and the normal probability plots indicated normal distributions. Examination of the residual frequency histograms and the scatterplots of the standardized residuals with the standardized predicted values of each variable indicated no violation of homoscedasticity.

Descriptive statistics indicated moderately high mean values for the WAI-T $(M=190.94, S D=$ 30.51 ; item $M=5.30$ on a 7 -point scale). Moderately high scores were also found for the TPRS-R total score $(M=48.03, S D=1.39$; item $M=4.00$ on a 5 point scale).

Reflecting the behavioral nature of the RBS, mean scores $(M=14.20, S D=5.42$; item $M=2.84$ on a 5point scale) on this measure were not as high as the average scores on the more subjective WAI-T and TPRS-R. The more moderate RBS scores reflect our intention for the measure to represent some but not all kinds of effective supervision behaviors. Notably, the mean RBS scores in the Study 2 sample did not differ significantly from those obtained in Study $1(M=14.23, S D=5.39)$.

Relational behavior and theoretical orientation. Replicating Study 1, we investigated whether supervisors' theoretical orientations would be associated with differing levels of relational behavior as perceived by trainees. Specifically, we predicted that compared with cognitive-behavioral supervisors $(n=50)$, psychoanalytic/psychodynamic and humanistic supervisors $(n=45)$ would be perceived by 
their supervisees as using significantly more insession relational behavior.

Results supported this hypothesis, $F(1,93)=31.43$, $p=.001, \eta^{2}=0.25$. Similar to Study 1, RBS scores were significantly higher for psychodynamic/ psychoanalytic/humanistic supervisors $(M=17.19$, $S D=4.51)$ than for cognitive-behavioral supervisors $(M=11.84, S D=4.76)$.

Confirmatory factor analysis. A confirmatory factor analysis (CFA) was conducted using LISREL statistical software to assess the construct validity of the 5 key items in the RBS. To ensure adequate statistical power for this analysis (only), the samples from Studies 1 and 2 were combined (total $N=262$ ).

A one-factor solution was tested to determine whether the five items identified in Study 1 (exploration of feelings, focus on the therapeutic process, attend to parallel process, focus on countertransference, and focus on the supervisory alliance) would comprise a single "relational behavior" factor. In CFA, goodness of fit is demonstrated by a small $\chi^{2}$ value with $p>.05$, non-normed fit index (NNFI) and comparative fit index (CFI) scores $>0.95$, root mean square error of approximation (RMSEA) < 0.06 and standardized root mean square residual $($ SRMR) < 0.08 (Hu \& Bentler, 1999; Kahn, 2006).

Maximum likelihood estimation indicated that the one-factor model was a good fit to the data based on these parameters. Specifically, $\chi^{2}(5, N=262)=$ $11.10 ; p=.049 ; \mathrm{NNFI}=0.98 ; \mathrm{CFI}=0.99$; RMSEA $=0.068, p=0.24$; and SRMR $=0.025$. Examination of the completely standardized solution Lambda values indicated that all factor loadings were significant at $\geq 0.67$ (see Table I). Moreover, the maximum likelihood solution indicated that the one-factor solution accounted for $53.58 \%$ of the overall variance.

Item-scale correlations indicated that dropping any of the five items would notably reduce the scale's internal consistency reliability. The internal consistency reliability estimate for the combined sample of 262 was $\alpha=0.85$, equivalent to the value found for each sample considered independently.
Tests of construct validity. Supporting the validity of the RBS, scores on the measure were strongly and positively correlated with WAI-T alliance scores, $r=0.62, r^{2}=0.38, p=.001$, as well as with total TPRS-R scores, $r=0.41, r^{2}=0.17, p=.001$. These results indicate that greater use of relational behavior in a specific supervision session contributed to a more favorable view of the supervisory alliance and a more positive overall experience in that session.

Next, we tested the indirect effect of RBS on the relation between WAI-T and the TPRS-R Evaluation of Supervisor subscale (see Figure 1). Based on Frazier, Tix, and Barron's (2004) approach to mediation, results indicated a strong overall effect, $R^{2}=0.703$, adj. $R^{2}=0.669, p<.0001$ (see Table II). The significance of the indirect effect was tested using Preacher and Hayes's (2004) suggestions and Hayes' (2014) SPSS Macro for Multiple Mediation. Results were significant, $p>.0001$, and a bootstrap re-sampling of 1000 found that the data (0.0115) and bootstrap $(0.0118)$ values were similar, $95 \% \mathrm{CI}$ $[0.0046,0.0216]$. These results signify that, as hypothesized, the strong relation between alliance perceptions and evaluation of the supervisor in a specific session was partially explained by the supervisor's perceived use of relational behaviors in that session, results that support the validity of the RBS.

\section{Discussion}

In a scholarly review of the training and supervision literature, Hill and Knox (2013) pointed to the paucity of research on the "impact of specific supervisor interventions on supervisees ..." (p. 789). The present program of research had as its objective to begin filling this gap.

Taken together, our results support Friedlander and Ward's (1984) conceptual model of quality supervision, in which four interrelated sources of variability among supervisors-from most to least global-are theoretical orientation, supervisory style, supervision format, and strategy. Specifically, as in Friedlander and Ward's samples, Study 1 participants reported that-in individual supervisionpsychodynamic/psychoanalytic/humanistic

Table I. CFA factor loadings and means and standard deviations for RBS items: Study 2.

\begin{tabular}{lccrr}
\hline Item & Factor loading & $M$ & $S D$ & Skewness \\
\hline Exploration of feelings & 0.83 & 3.23 & 1.36 & -0.22 \\
Focus on therapeutic process & 0.68 & 3.47 & 1.24 & -0.48 \\
Attend to parallel process & 0.67 & 2.21 & 1.34 & -1.16 \\
Focus on countertransference & 0.76 & 2.64 & 1.42 & 0.80 \\
Focus on supervisory alliance & 0.71 & 2.71 & 1.46 & 0.35 \\
\end{tabular}




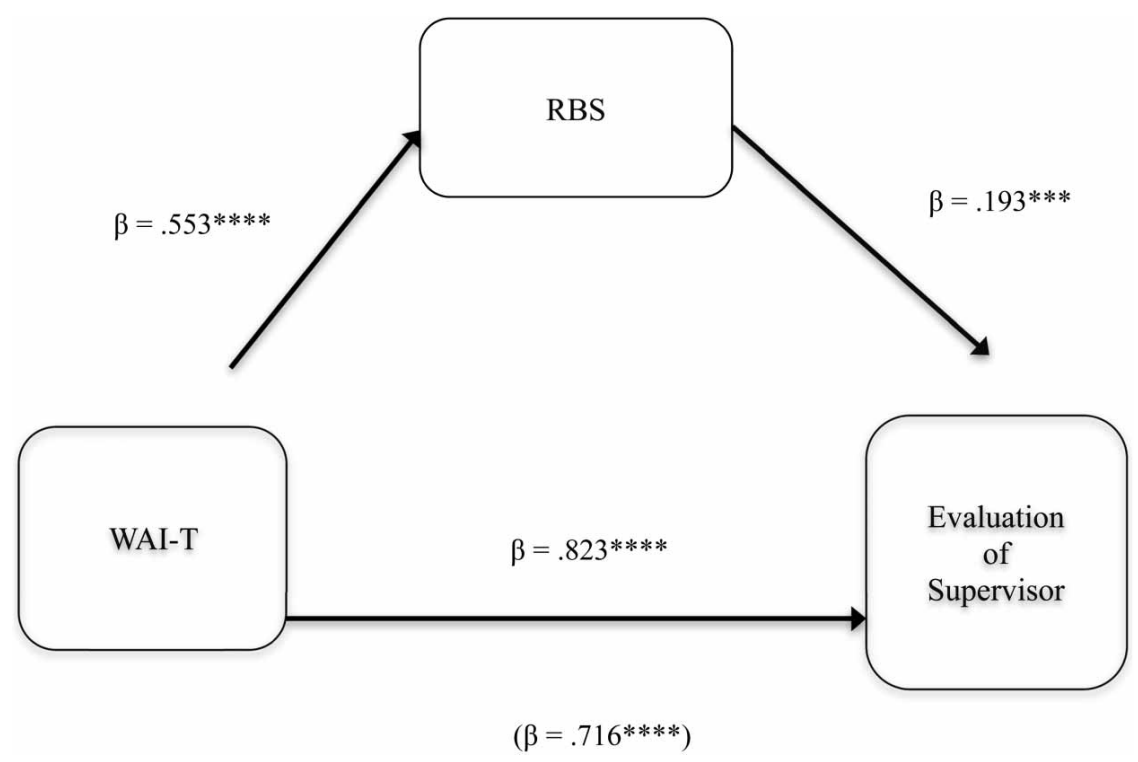

Figure 1. Path coefficients for mediation analysis, ${ }^{* * *} p<.001 .{ }^{* * * *} p<.0001$.

Note: $\beta$ in parenthesis signifies path $c^{\prime}$.

Table II. Tests of the mediation hypothesis: Study 2.

\begin{tabular}{lcccc}
\hline Steps in Mediation Model & $B$ & SE B & $95 \%$ CI & $\beta$ \\
\hline $\begin{array}{l}\text { Step 1 (path c) } \\
\quad \text { Outcome: Evaluation of Supervisor }\end{array}$ & & & & $0.823^{* * * *}$ \\
$\quad$ Predictor: WAI-T & 0.088 & 0.005 & $0.078,0.099$ & $0.553^{* * * *}$ \\
$\begin{array}{l}\text { Step 2 (path } a \text { ) } \\
\quad \text { Outcome: RBS }\end{array}$ & & & & \\
$\quad$ Predictor: WAI-T & 0.080 & 0.010 & $0.060,0.100$ & $0.193^{* * *}$ \\
Step 3 (path c') & & & & $0.716^{* * * *}$ \\
$\quad$ Outcome: Evaluation of Supervisor & 0.144 & 0.041 & $0.062,0.225$ & $0.065,0.089$ \\
$\quad \begin{array}{l}\text { Mediator: RBS (path } b \text { ) } \\
\text { Predictor: WAI-T }\end{array}$ & 0.077 & 0.006 & & \\
\hline
\end{tabular}

Note. $N=141$. Evaluation of Supervisor is one subscale within the TPRS-R (Holloway \& Wampold, 1984). WAI-T (Bahrick, 1989).

$F(2,138)=163.35, R^{2}=0.703$, adj. $R^{2}=0.669, p<.0001$. The semi-partial correlations in the path $c^{\prime}$ equation (Step 3) were 0.161 (RBS) and 0.597 (WAI-T).

${ }^{* * *} p<.001$.

${ }^{* * * *} p<.0001$.

supervisors were significantly more likely than cognitive-behavioral supervisors to adopt an IS style. Contributing to the validity of the model, our results further indicated that, in contrast to a TO or a collegial/"attractive" style of supervision, the IS style was uniquely associated with in-session use of relational behavior. Also in line with Friedlander and Ward's finding about the significant relation between IS supervision and trainees' perceptions of their professional development, Study 2 results showed that supervisors' use of relational behavior contributed $17 \%$ of the variance to participants' overall evaluations of the supervision experience.
Moreover, in line with the Critical Events model of supervision (Ladany et al., 2005, in press), we found that relational strategies accounted for $38 \%$ of the variance in trainees' perceptions of the supervisory working alliance. In other words, when participants viewed their supervisors as having used more of five key behaviors (exploration of feelings, focus on therapeutic process, attend to parallel process, focus on countertransference, and focus on supervisory alliance) in their most recent supervision session, they were likely to view the working relationship with their supervisors favorably. Even more salient were the results of the mediation 
analysis, which supported our hypothesis that the well documented association between alliance perceptions and evaluations of the supervisor (e.g., Ladany et al., 1999) could be accounted for, at least in part, by the supervisor's in-session use of relational behavior.

The significant association between in-session behavior and perceptions of the alliance is also important in light of the fact that neither construct reflects the overall competency of the supervisor or the quality of supervision in general. Nonetheless, a supervisor's use of relational behavior, as a strong contributor to the working alliance, seems to capture a salient aspect of supervision, that is, what a supervisor actually focuses on during an effective supervision session. An important next step seems to be to determine whether use of relational behavior in supervision predicts the trainee's relational focus in subsequent psychotherapy sessions with clients.

In both studies we found that the five behaviors that comprise the RBS score are most consistent with psychoanalytic/psychodynamic and humanistic approaches to psychotherapy. However, the behaviors that comprise the RBS are not unique to these theoretical approaches or to an interpersonal approach to supervision. Indeed, recall that scores on the three supervisory styles in the SSI (Friedlander \& Ward, 1984) shared $60 \%$ of the variance with scores on the RBS. In other words, cognitive-behavioral and task-focused supervisors also use these key relational behaviors, although apparently not to as great an extent or perhaps as consistently as more interpersonally oriented supervisors. Consider, for example, Safran et al.'s (2014) alliance focused training (AFT) in the supervision of cognitive psychotherapy, the goal of which is "to train therapists to use their own emerging feelings as important clues regarding what may be taking place in the therapeutic relationship" (p. 269). It is quite likely that despite teaching a cognitive approach to psychotherapy, AFT supervisors rely heavily on relational strategies in supervision; moreover, they expect that experiencing this relational focus in supervision will carry over to their trainees' work with clients.

In terms of limitations, it is possible that our participants were not able to recall their supervisors' relational behaviors or to recall them accurately. The two samples were nonrandom, and participants may have been particularly interested in supervision, introducing a possible self-selection bias. Since many volunteers were recruited for the study by their training directors, it is also possible that some participants reported on their experience with the same supervisor, introducing a non-independence bias. In addition, the results should not be generalized to post-graduate professionals in supervision or to the group format of supervision.

Another notable limitation has to do with the fact that all measures were administered simultaneously and the indirect effect of RBS, albeit significant, was small. For future research, we recommend a mediation design that accounts for temporal precedence. By staggering the administration of measures we could determine, for example, whether the frequency of in-session relational behavior assessed mid-semester significantly mediates the effect of early alliance perceptions on participants' experience of their supervisors several weeks later.

Although this was the first use of the RBS, it shows promise for future study on supervision processes. First, our research should be replicated and extended to assess the validity of the measure and provide more evidence of its utility in understanding the supervisory experience. Second, researchers should investigate the use of relational behavior in various contexts. It may be that supervisors rely on relational strategies during certain periods, rather than more generally over the course of supervision. Indeed, it is likely that supervisors use more or less relational behavior depending on the trainee's developmental level (e.g., beginner, advanced, and intern), the client(s) being discussed, the clinical setting, and institutional demands. In fact, the use of relational behavior in context reflects the construct supervisor responsiveness, which Friedlander defined as "the accurate attunement and adaptation to a supervisee's emerging needs ... with respect to the needs of the client(s) with whom the supervisee is working" (2012, p. 106).

Future researchers could also investigate whether there are "exceptional supervisors" (Ellis, Ayala, Kotary, Berger, \& Hanus, 2015) who tend to use relatively more relational behavior than others. If so, how do these supervisors learn to conduct relationally oriented supervision? Many supervisors, particularly those who were trained in decades past, may have not had formal training in supervision, inasmuch as academic preparation for supervision is a relatively new requirement in doctoral programs accredited by the APA.

Furthermore, the RBS can also be used to investigate Ladany et al.'s (2005, in press) Critical Events model in a task analytic fashion, by studying the specific relational interactions in supervision that lead to predictable in-session outcomes. Indeed, the five relational behaviors themselves merit further study. For instance, are there specific relational behaviors or sets of behaviors that are most successfully used to resolve supervisees' difficulties within, say, a sexual attraction critical event or a countertransference event? It may be important to understand 


\section{K. S. Shaffer and M. L. Friedlander}

whether or not there are predictable choice points in supervision that indicate a preference for selecting one relational behavior over another. If we find that supervisors use relational behaviors in a predictable way, this knowledge would facilitate theory-building around interpersonal supervision, as well as providing practical advice for novice supervisors.

More research is needed to replicate the significant relationship found in this study between relational behavior and the supervisory alliance. Future studies may include other important supervisory variables, such as non-disclosure, as they relate to RBS scores. Similarly, it is important to understand differences between supervisors who use relatively more relational behaviors and those who use less and how this difference can influence trainees' therapeutic alliances with their clients. As we noted earlier, several studies (e.g., Tracey et al., 2012) provided clear evidence of the parallel process phenomenon. Researchers may consider using the RBS in conjunction with a measure of the therapeutic alliance to understand how relational behavior on the part of the supervisor may carry over to a trainee's relationship with clients, and vice versa.

Finally, the significant results of this study may encourage researchers to expand theory and scale construction on other effective supervisory behaviors. Although we found relational behavior to be positively associated with alliance perceptions, there are likely other important behaviors that supervisors use to develop and maintain a strong working alliance, or to repair a rupture in the alliance (Friedlander, 2015). In other words, despite their importance, the five key relational behaviors in the RBS are not the only effective supervision behaviors. Indeed, the Critical Events model contains six other strategies (e.g., focus on evaluation, focus on multicultural awareness; see Appendix 1) that Ladany et al. (2005, in press) described as useful for addressing particular issues in supervision.

In sum, the present results notwithstanding, relationally oriented supervision is not the exclusively effective way to approach supervision. Indeed, as mentioned earlier we found that relational behaviors were also significantly (but not uniquely or as strongly) associated with the TO and ATT (i.e., collegial) styles of supervision. To put it differently, although our research program focuses on IS supervision, we do not assume that this approach is the only effective one. Nor do we assume that the five key relational behaviors that comprise the RBS are the only, or even the most salient, ones in supervision. For example, TO behaviors that facilitate learning for trainees may be more important than relational ones in certain situations, particularly for crisis management and risk assessment.
Nonetheless, given previous findings regarding the positive contributions of an IS supervisory style to the supervisory relationship, we believe it to be essential to understand specifically how supervisors cultivate a relational style of interacting with trainees. Only by understanding how supervisors actually behave in high-quality supervision can we train new supervisors to learn to conduct responsive supervision (Friedlander, 2012, 2015).

\section{Acknowledgements}

The two studies in this article were presented at annual conferences of the Society for Psychotherapy Research (2012) in Virginia Beach, VA, and (2015) in Philadelphia, PA. Study 2 was conducted as a dissertation by the first author under the direction of the second author and committee members Michael V. Ellis and Mary Lee Nelson.

\section{References}

Bahrick, A. S. (1989). Role induction for counselor trainees: Effects on the supervisory working alliance. Dissertation Abstracts International, 51, 1484B.

Bertsch, K. N., Bremer-Landau, J. D., Inman, A. G., DeBoer Kreider, E. R., Price, T. A., \& DeCarlo, A. L. (2014). Evaluation of the critical events in supervision model using gender related events. Training and Education in Professional Psychology, 8, 174-181.

Bordin, E. S. (1983). A working alliance based model of supervision. The Counseling Psychologist, 11, 35-42. doi:10.1177/ 0011000083111007

Doehrman, M. (1976). Parallel processes in supervision and psychotherapy. Bulletin of the Menninger Clinic, 40, 3-104.

Eckstein, R., \& Wallerstein, R. S. (1972). The teaching and learning of psychotherapy (2nd ed.). New York: International Universities Press.

Ellis, M. V., Ayala, E. E., Kotary, B., Berger, L., \& Hanus, A. (2015, August). Exceptional clinical supervision: Testing a taxonomy and assessing occurrence. In E. E. Ayala \& M. V. Ellis (Co-Chairs), Clinical supervision practices and self-care: Lifelong training implications for psychologists. Paper presented at the 123rd annual convention of the American Psychological Association, Toronto, Ontario.

Ellis, M. V., Berger, L., Hanus, A., Alaya, E. E., Siembor, M. J., \& Swords, B. A. (2014). Inadequate and harmful clinical supervision: Revising the framework and assessing occurrence. The Counseling Psychologist, 42, 434-472.

Frazier, P. A., Tix, A. P., \& Barron, K. E. (2004). Testing moderator and mediator effects in counseling psychology research. Fournal of Counseling Psychology, 51, 115-134.

Friedlander, M. L. (2012). Therapist responsiveness: Mirrored in supervisor responsiveness. The Clinical Supervisor, 31, 103-119.

Friedlander, M. L. (2015). Use of relational strategies to repair alliance ruptures: How responsive supervisors train responsive therapists. Psychotherapy, 52, 174-179.

Friedlander, M. L., Siegel, S. M., \& Brenock, K. (1989). Parallel processes in counseling and supervision: A case study. Fournal of Counseling Psychology, 36, 149-157. 
Friedlander, M. L., \& Ward, L. G. (1984). Development and validation of the supervisory styles inventory. Fournal of Counseling Psychology, 31, 541-557.

Hayes, A. F. (2014). INDIRECT (SPSS Macro) [Software]. Retrieved from http://www.afhayes.com/public/indirect.sps

Hess, A. K. (1980). Training models and the nature of psychotherapy supervision. In A. K. Hess (Ed.), Psychotherapy supervision: Theory, research, and practice (pp. 15-25). New York: Wiley.

Hill, C., \& Knox, S. (2013). Training and supervision in psychotherapy. In M. J. Lambert (Ed.), Bergin and Garfield's handbook of psychotherapy and behavior change (6th ed., pp. 775-811). New York: Wiley.

Holloway, E. L., \& Wampold, B. E. (1984, August). Dimensions of satisfaction in the supervision interview. Paper presented at the meeting of the American Psychological Association Convention, Toronto, Canada.

Hu, L. T., \& Bentler, P. M. (1999). Cutoff criteria for fit indexes in covariance structure analysis: Conventional criteria versus new alternatives. Structural Equation Modeling: A Multidisciplinary fournal, 6, 1-55.

Inman, A. G. (2006). Supervisor multicultural competence and its relation to supervisory process and outcome. Fournal of Marital and Family Therapy, 32, 73-85.

Kahn, J. H. (2006). Factor analysis in counseling psychology research, training, and practice principles, advances, and applications. The Counseling Psychologist, 34, 684-718.

Kell, B. L., \& Mueller, W. J. (1966). Impact and change: A study of counseling relationships. East Norwalk, CT: Appleton-CenturyCrofts.

Ladany, N., Ellis, M. V., \& Friedlander, M. L. (1999). The supervisory working alliance, trainee self-efficacy and satisfaction. fournal of Counseling and Development, 77, 447-455. doi:10. 1002/j.1556-6676.1999.tb02472.x

Ladany, N., \& Friedlander, M. L. (1995). The relationship between the supervisory working alliance and trainees' experiences of role conflict and role ambiguity. Counselor Education and Supervision, 34, 220-231. doi:10.1002/j.1556-6978.1995. tb00244.x

Ladany, N., Friedlander, M. L., \& Nelson, M. L. (2005). Critical events in psychotherapy supervision. Washington, DC: American Psychological Association.

Ladany, N., Friedlander, M. L., \& Nelson, M. L. (in press). Supervision essentials for the critical events model of psychotherapy

\section{Appendix 1. Relational behavior scale}

Think about your most recent supervisory session with the supervisor who (1) provides you with individual supervision and (2) if you have more than one, the supervisor whom you know best. Please read the following descriptions of behavior and thinking back to your most recent supervisory session, identify how much your supervisor employed each type of behavior, where $1=$ not at all and $5=$ very much.

1. Normalizing Experience:

A discussion of how the supervisee's experience, (either as a therapist, colleague, or supervision. Washington, DC: American Psychological Association.

Little, R. J. A. (1988). A test of missing completely at random for multivariate data with missing values. Fournal of the American Statistical Association, 83, 1198-1202.

Nelson, M. L., \& Friedlander, M. L. (2001). A close look at conflictual supervisory relationships: The trainee's perspective. fournal of Counseling Psychology, 48, 384-395.

Olk, M. E., \& Friedlander, M. L. (1992). Trainees' experiences in role conflict and role ambiguity in supervisory relationships. fournal of Counseling Psychology, 39, 389-397. doi:10.1037/ 0022-0167.39.3.389

Preacher, K. J., \& Hayes, A. F. (2004). SPSS and SAS procedures for estimating indirect effects in simple mediation models. Behavior Research Methods, Instruments and Computers, 36, 717-731.

Ramos- Sánchez, L., Esnil, E., Goodwin, A., Riggs, S., Touster, L. O., Wright, L. K., ... Rodolfa, E. (2002). Negative supervisory events: Effects on supervision satisfaction and the supervisory alliance. Psychology: Research and Practice, 33, 197-202. doi:10.1037/0735-7028.33.2.197

Safran, J., Muran, J. C., Demaria, A., Boutwell, C., EubanksCarter, C., \& Winston, A. (2014). Investigating the impact of alliance-focused training on interpersonal process and therapists' capacity for experiential reflection. Psychotherapy Research, 24, 269-285. doi:10.1080/10503307.2013.874054

Schlomer, G. L., Bauman, S., \& Card, N. A. (2010). Best practices for missing data management in counseling psychology. fournal of Counseling Psychology, 57, 1-10.

Searles, H. F. (1955). The informational value of the supervisor's emotional experiences. Psychiatry, 18(2), 135-146.

Stoltenberg, C. D., McNeill, B., \& Delworth, U. (1998). IDM supervision: An integrated developmental model for supervising counselors and therapists. San Francisco, CA: Jossey-Bass.

Tracey, T. J., Bludworth, J., \& Glidden-Tracey, C. E. (2012). Are there parallel processes in psychotherapy supervision? An empirical examination. Psychotherapy, 49, 330-343. doi:10. 1037/a0026246

Walker, J. A., Ladany, N., \& Pate-Carolan, L. M. (2007). Genderrelated events in psychotherapy supervision: Female trainee perspectives. Counselling and Psychotherapy Research, 7, 12-18.

supervisee) is typical and developmentally expected or appropriate

2. Exploration of Feelings: $\_1-2+3$ 5

Typically, but not exclusively, a here-and-now focus. Feelings can be expressed about the client, the therapeutic relationship or process, about the supervisee's progress in training, or about personal issues

3. Focus on Evaluation: $\_1 \_2-3 \_4$ 5

A discussion of the supervisee's performance in therapy, in supervision, and as a professional. May involve a discussion of feedback, critical and positive, either summative or formative 
4. Focus on Self-Efficacy: $\_1-2 \_3 \_4$ 5

A discussion of the supervisee's sense of confidence in his or her therapeutic skills (either specifically or globally), sense of self as a professional, or ability to function in various roles (e.g., therapist, student, supervisee, colleague)

5. Focus on Skill: __ $1 \_2 \_3 \_4 \_5$ A discussion of the how, when, where, and why of conceptual, technical and interpersonal skills. May include role-playing or a discussion of how to apply theory to specific therapy interventions

6. Focus on the Therapeutic Process: __ $1+2$ $3-4-5$

A discussion about what is taking place between the supervisee and client, i.e., the kinds of interactions that occur, the strength of the therapeutic alliance, and how the client sees the supervisee's behavior in relation to self and vice versa

7. Attend to Parallel Process: ___ $1 \_2 \_3 \_4$ 5

A discussion that draws attention to similarities between a specific therapeutic interaction and the supervisory interaction. Parallel processes may originate in either interaction and be mirrored in the other

8. Assessing Knowledge: $\_1 \_-2 \_3 \_4 \_5$ Evaluating the degree to which the supervisee is knowledgeable in areas relevant to the case(s) under discussion. Knowledge bases include ethics, research, and theory as applied to practice

9. Focus on Countertransference: $\_1-2 \_3$ 4

A discussion of how and why the supervisee's feelings and/or personal issues are "triggered" by a client's behavior or attitude

10. Focus on the Supervisory Alliance: __ $1 \ldots 2$ $3-4+5$

A discussion of aspects of the relationship related to agreement on the tasks and goals of supervision (including evaluation), as well as to the emotional bond between supervisor and supervisee. May either be a "checking in" about the alliance or an explicit discussion about what is taking place or should take place in supervision, including a focus on the supervisee's or the supervisor's feelings about their relationship

11. Focus on Multicultural Awareness: __ $1 \_2$ ${ }^{3}-4+5$

A discussion of the supervisee's self-awareness in relation to individuals who are similar and different from them in terms of gender, race, ethnicity, age, sexual orientation, religion, disability, family structure, or socio-economic status

The RBS score is the sum of items $2,6,7,9$, and 10 . 